\title{
The effects of regular and additional physical and health education classes on the qualitative changes of the situation motor abilities of female students in the $5^{\text {th }}$ grade of elementary school
}

\author{
- Elvira Nikšić ${ }^{1}, \odot$ Edin Beganović ${ }^{2}, \odot$ Faris Rašidagić $^{2} \odot$ Marko Joksimović $^{3}$
}

${ }^{1}$ Faculty of Educational Sciences, University of Sarajevo, Bosnia and Herzegovina. ${ }^{2}$ Faculty of Sport and Physical Education, University of Sarajevo, Bosnia and Herzegovina. ${ }^{3}$ Football club National, Podgorica, Montenegro.

\begin{abstract}
The aim of the research was to determine the effects of specially programmed physical and health education with the application of content from sports games (basketball, volleyball and handball) in the duration of one semester to qualitative changes in situational motor skills in students in the fifth grade of elementary school. The study included 106 pupils of the $\mathrm{V}$ class, aged 10 to 11 years, clinically and mentally healthy, and with no pronounced morphological and locomotor impairments. The sample of respondents was divided into two subgroups, an experimental group (53 pupils), who carried out physical education classes according to the modified plan and program of sports games (basketball, volleyball and handball) for a semester and a control group (53 pupils) who attended regular classes from physical education according to the current curriculum. In order to determine qualitative changes in situational motor abilities, descriptive statistics, T-test and factor analysis were usedThe results of the factor analysis show that there were statistically significant qualitative changes, and based on the results of $\mathrm{t}$-tests it can be concluded that they are statistically significant at levels less than $1 \%$ for the SMKVLS variable, and at levels less than $5 \%$ for the variables SMRBLZ and SMRVLS . In the final measurement, there was a change in value and thus a difference in the variables of the SMKBLK after the program of work.
\end{abstract}

Keywords. Modified plan and program, physical and health education, situational motors, sports games, students.

\section{Introduction}

Physical and health culture is an integral part of the educational process and has the task of positive transformation of personality dimensions throughout all ages (Prskalo \& Findak, 2003). To safely and efficiently affect the anthropological status of pupils by means of well-planned and programmed teaching content of physical education, their proper growth, development of their abilities, on the fund of motor knowledge and achievements, it is necessary to determine the current state of anthropological status of students, to determine the guidelines for their transformation and Provide feedback on the achieved level of transformations (Stankovic, 2002).

Transformation is a process in which the student, as a system, translates from one state to another. To raise the system to a higher level of program transformation, it is necessary to manage, ie to measure the system according to the desired direction, and this is only possible if we know the elements of the system itself and their mutual relations. The teaching process in the teaching of physical and health education is conceived as a specific transformation process, in which different means come to the transformations of the system itself. The tools represent techniques of sports games, elements of gymnastics and athletic discipline, as well as design exercises and natural habits of movement, all aimed at raising the level of the subject's abilities to a higher level, which will be reflected in improved health condition and an increased level of motor, situational motor, functional and other systems that make up the student's system. Lakota (2006) in his master's 
thesis on the sample of 82 handball players 11-14 years of age tried to determine the qualitative and quantitative changes in basic situational motor skills created under the influence of the threemonth program of handball. A 52-course handball program produced statistically significant changes in the treated areas. Hadžikadunić (2007), on a sample of 146 male students, identified transformation processes under the influence of programmed physical and health education for 69 hours of instruction in basic motor, situational and motor skills and functional abilities of students of the eighth grade. A system of variables of 8 tests for basic motor abilities and 9 tests for the assessment of specific motor abilities was used, and one test for the evaluation of functional abilities. It was found that programmed teaching has a positive impact on improving basic motor, situational and functional abilities between two measurements (initially and final). Mladenović (2008), in his paper "Structural changes in sports games in the teaching of physical education" on the sample of 152 students, carried out the contents of sports games in the teaching of physical education for the duration of one school year. By applying the treatment, the level of structural changes in basic and specific motors was attempted. The results of this program have shown a general, systematic, continuous reconstruction of general and specific motor abilities, therefore the transformation process is responsible, although not in all situations to the same extent. The worst effects are recorded in the case of football. Bajramović et al. (2008) on a sample of 103 footballers aged 12-14 years tried to determine the levels of transformation of motor skills and the success of footballers under the influence of sixmonth programmed work. Using the t-test for dependent samples at the univariate level, it was noted that the football program caused many significant changes after the final measurement. Using factor or discriminatory analysis at the multivariate level, the author concludes that significant global quantitative changes have occurred in the space of situational motor skills and success in the game, while weak changes were observed in the area of basic motor skills. Lakota et al. (2008) determined the qualitative level of transformation of situational motor skills in handball players aged 11-14 years in three months. The sample consisted of 82 male subjects. Factor analysis isolated $73 \%$ of the common variability. The results indicate that qualitative changes have been shown when hitting the goal with the ball, as well as the speed of movements related to ball control. Malacko \& Pejić (2009) have investigated the changes of biomotor pupils aged 11 years under the influence of the experimental program of sports games with the standard program of physical education. The sample was made up of 252 male students, who were divided into a control and experimental group. A system of 33 variables (12 morphological and 21 for estimation of motor and functional abilities) was used. The experimental program was saturated with the contents of sports games. The results indicate that the morphological system contributes to the same differentiation of the group, while the experimental group showed better results in the motor space, of which 14 variables showed a statistically significant difference in 13 variables, the experimental group was better. Džumhur (2009) investigated changes in motor skills and performance in a small soccer game using the situational method of work. On a sample of 81 subjects, aged 12-14 years. He established that the program with the application of the situational method of work revealed changes in the coordination segment, the speed of movement and the segment of equilibrium. It has positively influenced the improvement of situational performance in the soccer game.

The aim of this study was to determine the effects of specially programmed physical and health education with the application of content from sports games (basketball, volleyball, and handball) in one semester to qualitative changes in situational motor skills in students in the fifth grade of elementary school.

\section{Methods}

The study was conducted on a sample of 106 pupils in grade, female, aged 10 to 11 years, clinically and mentally healthy, and with no pronounced morphological and locomotor impairments. The sample of respondents was divided into two subgroups, an experimental (53 pupils) and a 
control group (53 students). The experimental group conducted classes according to the changed curriculum. The program included sports games from handball, basketball, and volleyball. The control group carried out the teaching according to the current curriculum. The selected variables in this study will hypothetically cover the situations of situational motorcycle 9 variables: basketball 3 variables, volleyball 3 variables, and handball 3 variables.

The study was approved by the Ethics Committee of the Faculty of Educational Sciences, University of Sarajevo, in accordance with the Declaration of Helsinki (World Medical Association, 2013). The study was supported by all parents, who gave their written consent. In the process of data processing at the univariate level for all variables, the central and dispersion parameters were calculated with the aim of establishing the basic indicators. The following descriptive parameters are calculated: Minimum value (Min); Maximum value (Max); Arithmetic mean (M); Standard deviation (SD); Skewness;
Kurtosis. Using the univariate T-test for dependent samples, the partial differences between the applied initial and final variation variables were determined. Using the univariate T-test for independent samples, differences in variables for assessing the situational motor performance of the initial and final test of the control and experimental group were determined. At the multivariate level, with the help of factor analysis, qualitative changes of situational motor skills were calculated under the influence of the experimental program in the final versus the initial measurement. Statistical data processing in this study was done using computer software SPSS statistics 20.0 in Windows 10.

\section{Work Program}

During the first semester, three teaching units were processed as part of regular classes: athletics, basketball and volleyball. A total of 35 teaching hours of regular physical education were held, of which 12 hours of athletics, 12 hours of basketball, 11 hours of volleyball.

\section{Table 1}

List of used tests for assessing situational motor performance in sports games.

\begin{tabular}{|c|c|c|c|}
\hline R.b. & Sports Games & Test Code & Test Name \\
\hline 1. & Basketball & SMKBLRZ & $\begin{array}{l}\text { Throwing the ball with your hands on the wall and catching it in } 30 \\
\text { seconds }\end{array}$ \\
\hline 2. & & SMKVLS & Running the ball with the hand in the slalom \\
\hline 3. & & SMKBLK & Throwing the ball into the basket for 30 seconds \\
\hline 4. & Volleyball & SMOSD & Service bottom corner \\
\hline 5. & & SMOGCPM & Hitting the target through over the net from the base position \\
\hline 6. & & SMOOLPK & Retraction of the forearms in the circle for 30 seconds \\
\hline 7. & & SMRBLZ & Throwing the ball against the wall for 30 seconds \\
\hline 8. & Handball & SMRVLS & Leading the ball in slalom \\
\hline 9. & & SMRIS & Performance of sevens \\
\hline
\end{tabular}


Table 2

Display of average values and measurements of variance of situational motor variables - Control and experimental group initially and final.

\begin{tabular}{|c|c|c|c|c|c|c|c|c|c|c|c|c|c|}
\hline \multirow{2}{*}{ Variables } & \multirow{2}{*}{ Group } & \multicolumn{2}{|c|}{ Min. } & \multicolumn{2}{|c|}{ Max. } & \multicolumn{2}{|c|}{ Mean } & \multicolumn{2}{|c|}{ SD } & \multicolumn{2}{|c|}{ Skewness } & \multicolumn{2}{|c|}{ Kurtosis } \\
\hline & & IT & FT & IT & FT & IT & FT & IT & FT & IT & FT & IT & FT \\
\hline \multirow{2}{*}{ SMKBLRZ } & Control & 5.00 & 17.00 & 33.00 & 36.00 & 23.38 & 26.66 & 5.20 & 4.02 & -1.05 & -0.19 & 2.22 & -0.05 \\
\hline & Experimental & 8.00 & 11.00 & 30.00 & 32.00 & 22.19 & 24.89 & 5.89 & 5.59 & -0.83 & -0.96 & 0.08 & 0.29 \\
\hline \multirow{2}{*}{ SMKVLS } & Control & 7.81 & 7.62 & 13.19 & 11.25 & 10.32 & 9.24 & 1.39 & 1.00 & 0.22 & 0.14 & -0.61 & -1.06 \\
\hline & Experimental & 7.72 & 7.09 & 18.94 & 16.16 & 11.41 & 10.21 & 2.64 & 1.97 & 0.91 & 0.80 & 0.30 & 0.49 \\
\hline \multirow{2}{*}{ SMKBLK } & Control & 1.00 & 2.00 & 13.00 & 13.00 & 4.17 & 6.58 & 2.52 & 2.56 & 1.18 & 0.62 & 1.89 & 0.08 \\
\hline & Experimental & 1.00 & 1.00 & 12.00 & 14.00 & 3.83 & 5.51 & 2.42 & 2.85 & 1.13 & 0.75 & 1.37 & 0.19 \\
\hline \multirow{2}{*}{ SMOSD } & Control & 1.00 & 2.00 & 12.00 & 12.00 & 6.72 & 8.89 & 3.07 & 2.49 & -0.12 & -0.74 & -0.97 & 0.11 \\
\hline & Experimental & 1.00 & 2.00 & 12.00 & 12.00 & 6.83 & 9.06 & 3.34 & 2.94 & -0.11 & -0.94 & -1.28 & -0.15 \\
\hline \multirow{2}{*}{ SMOGCPM } & Control & 1.00 & 2.00 & 8.00 & 9.00 & 4.34 & 6.30 & 2.36 & 2.05 & 0.11 & -0.36 & -1.23 & -0.72 \\
\hline & Experimental & 1.00 & 2.00 & 9.00 & 9.00 & 4.98 & 6.68 & 2.23 & 2.06 & -0.31 & -1.06 & -0.85 & 0.16 \\
\hline \multirow{2}{*}{ SMOOLPK } & Control & 7.00 & 8.00 & 32.00 & 33.00 & 18.34 & 21.83 & 4.93 & 5.36 & -0.21 & -0.01 & 0.71 & 0.42 \\
\hline & Experimental & 6.00 & 10.00 & 34.00 & 43.00 & 20.13 & 24.83 & 6.65 & 7.22 & -0.18 & -0.12 & -0.40 & -0.22 \\
\hline \multirow{2}{*}{ SMRBLZ } & Control & 12.00 & 14.00 & 30.00 & 32.00 & 21.42 & 23.45 & 3.86 & 3.94 & -0.16 & -0.06 & -0.11 & 0.06 \\
\hline & Experimental & 13.00 & 15.00 & 32.00 & 38.00 & 23.32 & 25.81 & 4.55 & 4.21 & -0.26 & 0.14 & -0.59 & 0.73 \\
\hline \multirow{2}{*}{ SMRVLS } & Control & 8.25 & 7.90 & 16.69 & 14.59 & 11.05 & 10.15 & 1.73 & 1.43 & 0.93 & 0.82 & 1.22 & 1.07 \\
\hline & Experimental & 7.97 & 7.75 & 20.15 & 15.03 & 11.90 & 10.57 & 2.33 & 1.80 & 1.13 & 0.50 & 1.90 & -0.56 \\
\hline \multirow{2}{*}{ SMRIS } & Control & 1.00 & 2.00 & 7.00 & 9.00 & 3.36 & 5.09 & 1.67 & 1.89 & 0.10 & 0.21 & -.98 & -0.68 \\
\hline & Experimental & 1.00 & 1.00 & 8.00 & 10.00 & 3.92 & 6.06 & 2.06 & 2.32 & 0.25 & -0.27 & -0.82 & -0.68 \\
\hline
\end{tabular}

The program of additional classes through the basketball, volleyball and handball sports games consisted of a modified curriculum from basketball: adding and catching balls from basketball, running a ball with a stop, a basketball technique, a low-lead technique, a kick-off practice with zipper positions, zigzag guiding, one - handed addition, moving the ball with arms in motion, running the ball with stop in the position of the shot, ball manipulation, pivoting technique with the ball, straight line guidance from high to low, and vice versa. From the volleyball sports, some teaching units worked, for example: adding a hammer, fingering over the net, school service, mini volleyball, hammering over the head, refusing As can be seen from Table 2. there are visible differences in the average values both between individual groups and between measurements the ball from the wall, adding alternating fingers a hammer, school service with six and nine meters, jumping with both legs on the net, shooting a basket with a hammer. From the handball, the teaching units worked as follows: foreclosure, lateral addition, jumping, kicking on the goal, slalom, handball, straight tracking, mini handball, goal kicking - seven, manipulation with a handball, Shade Adding, Adding To The Triples Game 1: 1 Shot on goal. Only girls were involved in this program and for this reason football was not taken as a sport game.

\section{Results}

within the same group. But these differences are identified at the descriptive level and can be a reflection of random variations, and their 
significance should be examined. According to the values of the Skewness and Kurtosis, it can be noticed that there are more mild variations in the normalities of some of the situations of situational motions. Thus, there is a mild negative asymmetry and elongation of the distribution of the results of the control group subjects on the variable SMKBLRZ (Throwing the Handle Hand with a Hand on the Wall for 30 seconds) in the initial measurement. The results on the variable SMKBLK (Throwing the ball into the basket for 30 seconds) were slightly elongated and positively asymmetrically distributed in the initial measurement both in the control and in the experimental group. In the initial testing, it was found that the distribution of results on SMOSD (Service Lower Cone), both in the control and experimental group, is slightly elongated but symmetrical. Results related to the variable SMRVLS (Running a slalom ball) were slightly elongated in the control group and additionally positively asymmetric in the experimental group. However, these deviations from the normalities are more boundary and these variables can be analyzed using parametric methods.

In the next part of the paper, a factorial analysis of the situational motors for the control group was made. For the analysis of the factual structure of the variables of the situational motor control group in the initial and final measurements, the method of the main components with oblimin factor rotation was used.

As can be seen from Tables 3 and 4, in the initial measurement of the control group, the extracted factors can explain at least $40 \%$ of the variance of one manifest variable of the situational motor (SMRIS variable) and at most $84 \%$ of one manifest variable of situational motors (variable SMKVLS). On the other hand, in the final measurement, the extracted factors can explain at least $21 \%$ of the variance of one manifest variable (variable SMRIS), and at most $81 \%$ of the variance of one manifest variable (variable SMKVLS).
Table 3

Communalities initially.

\begin{tabular}{lcc}
\hline Variables & Initial & Extraction \\
\hline SMKBLRZ & 1.00 & 0.62 \\
SMKVLS & 1.00 & 0.84 \\
SMKBLK & 1.00 & 0.47 \\
SMOSD & 1.00 & 0.56 \\
SMOGCPM & 1.00 & 0.73 \\
SMOOLPK & 1.00 & 0.48 \\
SMRBLZ & 1.00 & 0.55 \\
SMRVLS & 1.00 & 0.80 \\
SMRIS & 1.00 & 0.40 \\
\hline
\end{tabular}

Table 4

Communalities final.

\begin{tabular}{lcc}
\hline Variables & Initial & Extraction \\
\hline SMKBLRZ & 1.00 & 0.70 \\
SMKVLS & 1.00 & 0.81 \\
SMKBLK & 1.00 & 0.62 \\
SMOSD & 1.00 & 0.55 \\
SMOGCPM & 1.00 & 0.64 \\
SMOOLPK & 1.00 & 0.60 \\
SMRBLZ & 1.00 & 0.69 \\
SMRVLS & 1.00 & 0.77 \\
SMRIS & 1.00 & 0.21 \\
\hline
\end{tabular}

Analyzing the results of the initial and final measurements (Table 5 and 6), two situational motors in the control group were extracted. Both factors satisfy the criterion that they have the values of characteristic roots equal to or greater than 1. In the initial measurement, the factors explain $60.52 \%$ of the total variance of all manifest variables of situational motors in the control group, while this percentage in the final measurement is $62.20 \%$ (thus almost the same ). Such factor analysis results indicate a satisfactory factor structure of the manifest variables of situational motors in the control group, both initially and in the final measurement. 


\section{Table 5}

Matrix of characteristic roots and explained parts of common variance initially.

\begin{tabular}{|c|c|c|c|c|c|c|c|}
\hline \multirow{2}{*}{ Component } & \multicolumn{3}{|c|}{ Initial Eigenvalues } & \multicolumn{3}{|c|}{ Extraction Sums of Squared Loadings } & \multirow{2}{*}{$\begin{array}{c}\begin{array}{c}\text { Rotation Sums of } \\
\text { Squared Loadings }\end{array} \\
\text { Total }\end{array}$} \\
\hline & Total & $\%$ of Variance & Cumulative $\%$ & Total & $\%$ of Variance & Cumulative \% & \\
\hline 1 & 4.22 & 46.84 & 46.84 & 4.22 & 46.84 & 46.84 & 3.63 \\
\hline 2 & 1.23 & 13.68 & 60.52 & 1.23 & 13.68 & 60.52 & 3.35 \\
\hline 3 & 0.95 & 10.51 & 71.03 & & & & \\
\hline 4 & 0.72 & 8.02 & 79.05 & & & & \\
\hline 5 & 0.68 & 7.50 & 86.55 & & & & \\
\hline 6 & 0.45 & 4.95 & 91.50 & & & & \\
\hline 7 & 0.33 & 3.63 & 95.13 & & & & \\
\hline 8 & 0.28 & 3.15 & 98.28 & & & & \\
\hline 9 & 0.15 & 1.72 & 100.00 & & & & \\
\hline
\end{tabular}

Table 6

Matrix of characteristic roots and explained parts of the common variance final.

\begin{tabular}{|c|c|c|c|c|c|c|c|}
\hline \multirow{2}{*}{ Component } & \multicolumn{3}{|c|}{ Initial Eigenvalues } & \multicolumn{3}{|c|}{ Extraction Sums of Squared Loadings } & \multirow{2}{*}{$\begin{array}{c}\begin{array}{c}\text { Rotation Sums of } \\
\text { Squared Loadings }\end{array} \\
\text { Total }\end{array}$} \\
\hline & Total & $\%$ of Variance & Cumulative \% & Total & $\%$ of Variance & Cumulative \% & \\
\hline 1 & 4.24 & 47.14 & 47.14 & 4.24 & 47.14 & 47.14 & 3.67 \\
\hline 2 & 1.36 & 15.06 & 62.20 & 1.36 & 15.06 & 62.20 & 3.31 \\
\hline 3 & 0.98 & 10.88 & 73.08 & & & & \\
\hline 4 & 0.61 & 6.75 & 79.83 & & & & \\
\hline 5 & 0.57 & 6.30 & 86.13 & & & & \\
\hline 6 & 0.49 & 5.48 & 91.61 & & & & \\
\hline 7 & 0.33 & 3.71 & 95.33 & & & & \\
\hline 8 & 0.25 & 2.82 & 98.15 & & & & \\
\hline 9 & 0.17 & 1.85 & 100.00 & & & & \\
\hline
\end{tabular}

In original, non-rotated matrices of factor saturation, it is seen that in the initial and final measurements, all manifest variables of situational motions are grouped around the first factor. However, since the first factor is always a simple linear combination of manifest variables and explains why the most total variances, such a factorization result can reflect a pure artifact of the very extraction technique itself. In addition, a second factor having a characteristic root value greater than 1 is extracted, and a more adequate factor solution is needed. Therefore, a twin rotation of the rotation was used, the results of which are shown in the next section of the paper.

In the below matrices, the factor structures are given the representations of factor saturation, i. correlation of variables of manifest variables of situational motors with their factors. According to the values of these coefficients it can be noticed that the variables SMKBLRZ, SMOSD, SMOGCPM, SMOOLPK and SMRBLZ are grouped around the first factor around the first factor, while SMKVLS, 
SMKBLK, SMRVLS and SMRIS are grouped around the other factor. When it comes to the final measurement of the control group around the first factor, the manifest variables SMKBLRZ, SMOSD, SMOGCPM, SMOOLPK and SMRBLZ are grouped around the other SMKVLS, SMKBLK, SMRVLS and SMRIS. This represents the identical and invariant factor structure as well as in the initial measurement. Thus, after the rotation, a balanced factor structure of the situation motions variables in the group's control was achieved both in the initial and the final measurements.

Table 7. Matrix of isolated main components initially.

\begin{tabular}{lcc}
\hline \multirow{2}{*}{ Variables } & \multicolumn{2}{c}{ Component } \\
\cline { 2 - 3 } & 1 & 2 \\
\hline SMKBLRZ & 0.70 & 0.35 \\
SMKVLS & -0.70 & 0.59 \\
SMKBLK & 0.65 & -0.20 \\
SMOSD & 0.74 & 0.14 \\
SMOGCPM & 0.76 & 0.40 \\
SMOOLPK & 0.61 & 0.34 \\
SMRBLZ & 0.66 & 0.33 \\
SMRVLS & -0.76 & 0.47 \\
SMRIS & 0.56 & -0.30 \\
\hline
\end{tabular}

Table 8

Matrix of isolated main components final.

\begin{tabular}{lcc}
\hline \multirow{2}{*}{ Variables } & \multicolumn{2}{c}{ Component } \\
\cline { 2 - 3 } & 1 & 2 \\
\hline SMKBLRZ & 0.75 & 0.36 \\
SMKVLS & -0.72 & 0.54 \\
SMKBLK & 0.66 & -0.44 \\
SMOSD & 0.73 & 0.16 \\
SMOGCPM & 0.71 & 0.38 \\
SMOOLPK & 0.63 & 0.45 \\
SMRBLZ & 0.79 & 0.24 \\
SMRVLS & -0.72 & 0.51 \\
SMRIS & 0.40 & -0.23 \\
\hline
\end{tabular}

Table 9

Matrix structure initially.

\begin{tabular}{lcc}
\hline \multirow{2}{*}{ Variables } & \multicolumn{2}{c}{ Component } \\
\cline { 2 - 3 } SMKBLRZ & 1 & 2 \\
SMKVLS & 0.79 & -0.41 \\
SMKBLK & -0.36 & 0.91 \\
SMOSD & 0.49 & -0.66 \\
SMOGCPM & 0.72 & -0.55 \\
SMOOLPK & 0.86 & -0.42 \\
SMRBLZ & 0.69 & -0.33 \\
SMRVLS & 0.74 & -0.38 \\
SMRIS & -0.47 & 0.90 \\
\hline
\end{tabular}

Table 10

Matrix structure final.

\begin{tabular}{lcc}
\hline \multirow{2}{*}{ Variables } & \multicolumn{2}{c}{ Component } \\
\cline { 2 - 3 } & 1 & 2 \\
\hline SMKBLRZ & 0.83 & -0.41 \\
SMKVLS & -0.40 & 0.90 \\
SMKBLK & 0.39 & -0.79 \\
SMOSD & 0.72 & -0.51 \\
SMOGCPM & 0.80 & -0.36 \\
SMOOLPK & 0.77 & -0.27 \\
SMRBLZ & 0.82 & -0.51 \\
SMRVLS & -0.41 & 0.88 \\
SMRIS & 0.26 & -0.46 \\
\hline
\end{tabular}

In the factor matrices assebmly is given a representation of saturation factors in the form of weight (which denote the proportion of factor proportions of one factor in the manifest variable when the second factor is removed and vice versa). The form of these weights, as it can be seen, follows the factors of factor saturation and that the weight of the factor in the target manifest variable is higher, and if the weight is smaller and the factor share in the variance of the manifest variable is smaller. On the basis of these coefficients, for each of the control group members, the most likely 
factual result in the initial and final measurement can be predicted.

\section{Table 11}

Matrix assembly initially.

\begin{tabular}{lcc}
\hline \multirow{2}{*}{ Variables } & \multicolumn{2}{c}{ Component } \\
\cline { 2 - 3 } & 1 & 2 \\
\hline SMKBLRZ & 0.79 & 0.00 \\
SMKVLS & 0.14 & 0.98 \\
SMKBLK & 0.21 & -0.55 \\
SMOSD & 0.60 & -0.24 \\
SMOGCPM & 0.87 & 0.03 \\
SMOOLPK & 0.71 & 0.04 \\
SMRBLZ & 0.74 & 0.01 \\
SMRVLS & -0.01 & 0.89 \\
SMRIS & 0.06 & -0.60 \\
\hline
\end{tabular}

Table 12

Matrix assembly final.

\begin{tabular}{lcc}
\hline \multirow{2}{*}{ Variables } & \multicolumn{2}{c}{ Component } \\
\cline { 2 - 3 } & 1 & 2 \\
\hline SMKBLRZ & 0.83 & -0.01 \\
SMKVLS & 0.04 & 0.92 \\
SMKBLK & 0.01 & -0.78 \\
SMOSD & 0.62 & -0.21 \\
SMOGCPM & 0.81 & 0.03 \\
SMOOLPK & 0.83 & 0.13 \\
SMRBLZ & 0.74 & -0.16 \\
SMRVLS & 0.01 & 0.89 \\
SMRIS & 0.05 & -0.44 \\
\hline
\end{tabular}

Table 13

Matrix of intercorelation of isolated factors initially.

\begin{tabular}{ccc}
\hline Component & 1 & 2 \\
\hline 1 & 1.00 & \\
2 & -0.52 & 1.00 \\
\hline
\end{tabular}

Table 14

Matrix of intercorelation of isolated factors final.

\begin{tabular}{ccc}
\hline Component & 1 & 2 \\
\hline 1 & 1.00 & \\
2 & -0.48 & 1.00 \\
\hline
\end{tabular}

The intercorelation matrices indicate a significant overlap of the factors both in the initial and in the final measurement, since intermediate correlations are central to their values. The interdependence of factor structures is unchanged in the final versus the initial measurement of situational motoring.

Factor analysis was also carried out on the results related to the situational engine of the experimental group in the initial and final measurement. Also, in this analysis the method of the main components with oblique swinging rotation was used. The results of the analysis are shown in the following tables.

\section{Table 15}

Communalities initially.

\begin{tabular}{lcc}
\hline Variables & Initial & Extraction \\
\hline SMKBLRZ & 1.00 & 0.80 \\
SMKVLS & 1.00 & 0.73 \\
SMKBLK & 1.00 & 0.57 \\
SMOSD & 1.00 & 0.51 \\
SMOGCPM & 1.00 & 0.55 \\
SMOOLPK & 1.00 & 0.61 \\
SMRBLZ & 1.00 & 0.79 \\
SMRVLS & 1.00 & 0.77 \\
SMRIS & 1.00 & 0.54 \\
\hline
\end{tabular}

According to the values of the communality in the above tables, it can be seen that in the initial measurement, the extracted factor can, on average, explain from at least $51 \%$ of the variance of one manifest variable (SMOSD variable) to a maximum of $80 \%$ of the variance of an entire manifest variable (variable SMKBLRZ). In the final measurements, 
according to the values of utilities, it can be concluded that the extracted factor can explain between $52 \%$ of the variance of an entire manifest variable (SMKBLK variable) and $81 \%$ of the variance of an entire manifest variable (variable SMRVLS).

\section{Table 16}

Communalities final.

\begin{tabular}{lcc}
\hline Variables & Initial & Extraction \\
\hline SMKBLRZ & 1.00 & 0.77 \\
SMKVLS & 1.00 & 0.82 \\
SMKBLK & 1.00 & 0.52 \\
SMOSD & 1.00 & 0.59 \\
SMOGCPM & 1.00 & 0.56 \\
SMOOLPK & 1.00 & 0.59 \\
SMRBLZ & 1.00 & 0.70 \\
SMRVLS & 1.00 & 0.81 \\
SMRIS & 1.00 & 0.53 \\
\hline
\end{tabular}

Factor analysis of the situation of the situational motor in the experimental group was separated by one factor with values of the characteristic root greater than 1 in the initial and final measurements (characteristic root $=5.88$ in the initial 5.89 in the final measurement). In the initial measurement, the extracted factor can explain $65.29 \%$ of the total variance of all manifest variables. In the final measurement, the factor can explain $65.47 \%$ of the total variance of all manifest variables of situational motors. And for the initial and final measurement, the criterion of minimum $50 \%$ of the total variance explained. In both metering modes this is a pure and one-dimensional factor structure of the situational motors variables in the experimental group, as opposed to the control group where there are two latent factors in the structure of the situational motors. Since differences in factor structures occur in both initial and final measurements, it can not be safely assumed that the program has led to structural changes in the experimental group.

Table 17

Matrix of characteristic roots and explained parts of common variance initially.

\begin{tabular}{|c|c|c|c|c|c|c|}
\hline \multirow[b]{2}{*}{ Component } & \multicolumn{3}{|c|}{ Initial Eigenvalues } & \multicolumn{3}{|c|}{ Extraction Sums of Squared Loadings } \\
\hline & Total & $\%$ of Variance & Cumulative \% & Total & $\%$ of Variance & Cumulative \% \\
\hline 01 & 5.88 & 65.29 & 65.29 & 5.88 & 65.29 & 65.29 \\
\hline 2 & 0.78 & 8.67 & 73.96 & & & \\
\hline 3 & 0.61 & 6.77 & 80.73 & & & \\
\hline 4 & 0.48 & 5.38 & 86.11 & & & \\
\hline 5 & 0.40 & 4.41 & 90.52 & & & \\
\hline 6 & 0.33 & 3.71 & 94.23 & & & \\
\hline 7 & 0.25 & 2.76 & 96.99 & & & \\
\hline 8 & 0.16 & 1.75 & 98.74 & & & \\
\hline 9 & 0.11 & 1.26 & 100.00 & & & \\
\hline
\end{tabular}




\section{Table 18}

Matrix of characteristic roots and explained parts of the common variance final.

\begin{tabular}{ccccccc}
\hline \multirow{2}{*}{ Component } & \multicolumn{3}{c}{ Initial Eigenvalues } & \multicolumn{2}{c}{ Extraction Sums of Squared Loadings } \\
\cline { 2 - 6 } & Total & \% of Variance & Cumulative \% & Total & \% of Variance & Cumulative \% \\
\hline 1 & 5.89 & 65.47 & 65.47 & 5.89 & 65.47 & 65.47 \\
2 & 0.76 & 8.47 & 73.94 & & & \\
3 & 0.65 & 7.23 & 81.17 & & \\
4 & 0.50 & 5.54 & 86.71 & & \\
5 & 0.35 & 3.91 & 90.62 & & \\
6 & 0.32 & 3.53 & 94.16 & & \\
7 & 0.23 & 2.61 & 96.77 & & \\
8 & 0.22 & 2.40 & 99.17 & & & \\
9 & 0.07 & 0.83 & 100.00 & & & \\
\hline
\end{tabular}

Table 19

Matrix of isolated main components initially.

\begin{tabular}{lc}
\hline & Component \\
\cline { 2 - 2 } Variables & 1 \\
\hline SMKBLRZ & 0.89 \\
SMKVLS & -0.85 \\
SMKBLK & 0.75 \\
SMOSD & 0.71 \\
SMOGCPM & 0.74 \\
SMOOLPK & 0.78 \\
SMRBLZ & 0.89 \\
SMRVLS & -0.88 \\
SMRIS & 0.74 \\
\hline
\end{tabular}

Above is shown the saturation of the individual factors in the initial and final measurements. As can be seen from the coefficient of saturation, ie, correlation with factors, all variables are highly saturated by one factor and in initial and final measurements, and the height of coefficients does not vary much in value. Since it is a single-factor structure, no twist rotation is performed.

As can be seen from the table 21, t-tests are statistically significant at levels of less than $1 \%$ for the SMKVLS variable, and at levels less than $5 \%$ for the variables SMRBLZ and SMRVLS. Thus, the control and experimental group statistically
Table 20

Matrix of isolated main components final.

\begin{tabular}{lc}
\hline Variables & Component \\
\cline { 2 - 3 } & 1 \\
\hline SMKBLRZ & 0.88 \\
SMKVLS & -0.90 \\
SMKBLK & 0.72 \\
SMOSD & 0.77 \\
SMOGCPM & 0.75 \\
SMOOLPK & 0.77 \\
SMRBLZ & 0.83 \\
SMRVLS & -0.90 \\
SMRIS & 0.73 \\
\hline
\end{tabular}

significantly differ in the results of these three variables of situational motors. When looking at the average values from Table 2, the control group has fewer average values compared to the experimental group at SMKVLS (Mcontrol $=10.32$ and Mexperimental $=11.41), \operatorname{SMRBLZ}\left(M_{\text {control }}=21.42\right.$ and Mexperimental $=23.32)$ and SMRVLS (M control $=11.05$ and Mexperimental $=11.90)$. It can be concluded that in the initial measurement, the experimental group has statistically significantly higher values for the three variables of situational motors compared to the control group. In the results of other variables of situational motions between groups there are no 
statistically significant differences in the initial measurement.

As can be seen in table 22, t-tests are statistically significant for SMKVLS variables (significantly less than $1 \%$, i.e. $\mathrm{p}<0.01$ ), SMKBLK (significantly less than $5 \%$, i.e. $\mathrm{p}<0.05$ ), SMOOLPK ( significantly at the level of less than $5 \%$, i.e. $p<0.05)$, SMRBLZ (significantly less than $1 \%$, i.e. $\mathrm{p}<0.01$ ) and SMRIS (significantly less than $5 \%$, i.e. $p<0.05$ ). On these variables there is a significant difference between the control and the experimental group in the final measurement. On average, in the final measurement, the experimental group has higher values of the results on the variables SMKVLS $($ Mcontrol $=9.24$ a Mexperimental $=10.21)$, SMOOLPK $\left(M_{\text {control }}=21.83\right.$ a Mexperimental $\left.=24.83\right)$, SMRBLZ $\left(M_{\text {control }}=23.45\right.$ a Mexperimental $\left.=25.81\right)$ and SMRIS (Mcontrol $=5.09$ a Mexperimental $=6.06)$. And in the initial measurement, the experimental group had significantly higher values on the variables SMKVLS ( $\mathrm{M}_{\text {control }}=10.32$ and $\left.M_{\text {experimental }}=11.41\right)$ and SMRBLZ (Mcontrol $=21.42$ and Mexperimental $=23.32)$. However, in addition to these, a significant difference in averages and in favor of the experimental group in the final measurement occurs on the variables SMOOLPK and SMRIS where the experimental group has higher average values. In the initial measurement, the experimental group had higher values on the SMRVLS variables (Mcontrol $=11.05$ and $M_{\text {experimental }}=$ 11.90), but this significant difference in the final measurement was lost. Thus, the differences in favor of the experimental group were maintained on some variables, on some variables they became significant and on some variables they were lost in the final measurement.

\section{Table 21}

Values of t-test situational motors initial measurement.

\begin{tabular}{|c|c|c|c|c|}
\hline \multirow{2}{*}{ Variables } & \multirow{2}{*}{$t$} & \multirow{2}{*}{$\mathrm{p}$} & \multicolumn{2}{|c|}{$95 \%$ Confidence Interval of the Difference } \\
\hline & & & Lower & Upper \\
\hline \multirow[t]{2}{*}{ SMKBLRZ } & 1.10 & 0.27 & -0.95 & 3.33 \\
\hline & 1.10 & 0.27 & -0.95 & 3.33 \\
\hline \multirow[t]{2}{*}{ SMKVLS } & -2.66 & 0.01 & -1.90 & -0.28 \\
\hline & -2.66 & 0.01 & -1.91 & -0.27 \\
\hline \multirow[t]{2}{*}{ SMKBLK } & 0.71 & 0.48 & -0.61 & 1.29 \\
\hline & 0.71 & 0.48 & -0.61 & 1.29 \\
\hline \multirow[t]{2}{*}{ SMOSD } & -0.18 & 0.86 & -1.35 & 1.12 \\
\hline & -0.18 & 0.86 & -1.35 & 1.12 \\
\hline \multirow[t]{2}{*}{ SMOGCPM } & -1.44 & 0.15 & -1.53 & 0.24 \\
\hline & -1.44 & 0.15 & -1.53 & 0.24 \\
\hline \multirow[t]{2}{*}{ SMOOLPK } & -1.58 & 0.12 & -4.05 & 0.46 \\
\hline & -1.58 & 0.12 & -4.05 & 0.46 \\
\hline \multirow[t]{2}{*}{ SMRBLZ } & -2.33 & 0.02 & -3.53 & -0.28 \\
\hline & -2.33 & 0.02 & -3.53 & -0.28 \\
\hline \multirow[t]{2}{*}{ SMRVLS } & -2.14 & 0.03 & -1.64 & -0.06 \\
\hline & -2.14 & 0.04 & -1.64 & -0.06 \\
\hline \multirow[t]{2}{*}{ SMRIS } & -1.55 & 0.12 & -1.29 & 0.16 \\
\hline & -1.55 & 0.12 & -1.29 & 0.16 \\
\hline
\end{tabular}




\section{Table 22}

The values of the T-test situation motors final measurement.

\begin{tabular}{|c|c|c|c|c|}
\hline \multirow{2}{*}{ Variables } & \multirow{2}{*}{$t$} & \multirow{2}{*}{$\mathrm{p}$} & \multicolumn{2}{|c|}{$95 \%$ Confidence Interval of the Difference } \\
\hline & & & Lower & Upper \\
\hline \multirow[t]{2}{*}{ SMKBLRZ } & 1.88 & 0.06 & -0.10 & 3.65 \\
\hline & 1.88 & 0.06 & -0.10 & 3.65 \\
\hline \multirow[t]{2}{*}{ SMKVLS } & -3.18 & 0.00 & -1.57 & -0.36 \\
\hline & -3.18 & 0.00 & -1.57 & -0.36 \\
\hline \multirow[t]{2}{*}{ SMKBLK } & 2.04 & 0.04 & 0.03 & 2.12 \\
\hline & 2.04 & 0.04 & 0.03 & 2.12 \\
\hline \multirow[t]{2}{*}{ SMOSD } & -0.32 & 0.75 & -1.22 & 0.88 \\
\hline & -0.32 & 0.75 & -1.22 & 0.88 \\
\hline \multirow[t]{2}{*}{ SMOGCPM } & -0.94 & 0.35 & -1.17 & 0.42 \\
\hline & -0.94 & 0.35 & -1.17 & 0.42 \\
\hline \multirow[t]{2}{*}{ SMOOLPK } & -2.43 & 0.02 & -5.45 & -0.55 \\
\hline & -2.43 & 0.02 & -5.45 & -0.55 \\
\hline \multirow[t]{2}{*}{ SMRBLZ } & -2.98 & 0.00 & -3.93 & -0.79 \\
\hline & -2.98 & 0.00 & -3.93 & -0.79 \\
\hline \multirow[t]{2}{*}{ SMRVLS } & -1.33 & 0.19 & -1.05 & 0.21 \\
\hline & -1.33 & 0.19 & -1.05 & 0.21 \\
\hline \multirow[t]{2}{*}{ SMRIS } & -2.34 & 0.02 & -1.78 & -0.15 \\
\hline & -2.34 & 0.02 & -1.78 & -0.15 \\
\hline
\end{tabular}

Additionally, in the initial measurement, there were no significant differences in the SMKBLK variables, but in the final measurement it was determined that the control group had statistically significantly higher values on this variable (Mcontrol $=6.58$ and Mexperimental = 5.51). From this it can be seen that there has been a change in the value and therefore a difference in the described variables after the program of work. In this way, it was established that the program led to changes in the value of situational motoring to a greater extent in the experimental group. As for other situational motions variables that are not listed in the text, there are no differences between the groups in the final measurement.

\section{Discussion}

Previous research on the student population shows that properly programmed teaching or training processes contribute and help to the overall correct growth and development of children (Skender, 2003; Tabaković et al., 2006; Ćeleš, 2009). Therefore, it is very important in the process of operationalization that the appropriate instruments monitor the effects of teaching or training processes at each stage. The results of scientific research and practical experience (Amstrong et al., 1994; Milanovic, 2007) confirmed a sample of young athletes, pupils of elementary schools, that the gradual increase in progressive load in training work for the development of motor and functional abilities is particularly important the basics on which the situational motor skills will be universally developed. Hadžikadunić (2007), on a sample of 146 male students, identified transformation processes under the influence of programmed physical and health education for 69 hours of instruction in basic motor, situational and motor skills and functional abilities of students of 
the eighth grade. A system of variables of 8 tests for basic motor abilities and 9 tests for the assessment of specific motor abilities was used, and one test for the evaluation of functional abilities. It was found that programmed teaching has a positive impact on the improvement of basic motor, situational and functional abilities between two measurements (initially and final). Mladenović (2008), in his paper "Structural changes in sports games in the teaching of physical education" on the sample of 152 students, carried out the contents of sports games in the teaching of physical education for the duration of one school year. By applying the treatment, the level of structural changes in basic and specific motors was attempted. The results of this program have shown a general, systematic, continuous reconstruction of general and specific motor abilities, therefore the transformation process is responsible, although not in all situations to the same extent. The worst effects are recorded in the case of football. Bajramovic (2008), on a sample of 103 footballers aged 12-14 years, tried to determine the levels of transformation of motor skills and the success of footballers under the influence of six-month programmed work. Using the t-test for dependent samples at the univariate level, it was noted that the football program caused a number of significant changes after the final measurement. Using factor or discriminatory analysis at the multivariate level, the author concludes that significant global quantitative changes have occurred in the space of situational motor skills and success in the game, while weak changes were observed in the area of basic motor skills. Lakota et al. (2008) determined the qualitative level of transformation of situational motor skills in handball players aged 11-14 years in duration of three months. The sample consisted of 82 male subjects. Factor analysis isolated $73 \%$ of the common variability. The results indicate that qualitative changes have been shown when hitting the goal with the ball, as well as the speed of movements related to ball control. Malacko \& Pejić (2009) have investigated the changes of biomotor pupils aged 11 years under the influence of the experimental program of sports games in relation to the standard program of physical education. The sample was made up of 252 male students, who were divided into a control and experimental group. A system of 33 variables (12 morphological and 21 for estimation of motor and functional abilities) was used. The experimental program was saturated with the contents of sports games. The results indicate that the morphological system contributes to the equal differentiation of the group, while the experimental group showed better results in the motor space, of 14 variables, which showed a statistically significant difference in 13 variables, was an experimental group. Džumhur (2009) investigated changes in motor skills and performance in a small soccer game using the situational method of work. On a sample of 81 subjects, aged 12-14 years. He established that the program with the application of the situational method of work revealed changes in the coordination segment, the speed of movement and the segment of equilibrium. It has positively influenced the improvement of situational performance in the soccer game. Based on the results of the arithmetic meanings in the tests for the assessment of situational-motor abilities, at the beginning and at the end of the programmed exercise from volleyball, and on the basis of the significance of the changes tested with the T-test for the dependent samples, it is clearly visible that the programmed exercise from volleyball produced significant partial effects. In tests for assessment of situational-motor abilities, presented in this research by the variables SMJAPT - Japanese test, SMTESJ - seating test, SMPRSE - precision of serving, SOPKNZ - rejection of the ball in a circle on the wall and SOPPOZ - rejection of the ball with forearms on the wall, there is a statistically significant positive shift in the value of the arithmetic mean in all tested variables on the final measurement at the statistically most significant level. The results of the T-test of all variables for assessing situational motor abilities show statistically significant differences between the initial and final measurements at the Sig level. 0.00, which means that volleyball training was programmed, which was conducted with the tested group of respondents, produced significant partial effects in the area of the tested segments of the situational-motor space (Šmigalović et al., 2012). Analyzing the results of the final with respect to the initial situation of situational - motor abilities, there has been a rewriting of the variables and an 
increase in the number of factors, which shows that there have been qualitative changes in the structure, as well as the transformation of some numerical indicators of situational - motor abilities of the respondents. Looking at the whole, the program of regular and additional teaching with its contents and training exercises and loads had a significant influence on the qualitative changes in situational and motor skills (Talović et al., 2015).

\section{Conclusion}

This research was conducted with the aim of determining the effects of specially programmed physical and health education with the application of content from sports games (basketball, volleyball and handball) in the duration of one semester to qualitative changes in situational motor skills in pupils of the fifth grade of elementary school. The sample of respondents included 106 pupils in the class, aged 10 to 11 years, clinically and mentally healthy, and with no pronounced morphological and locomotor impairments. The sample of respondents was divided into two subgroups, an experimental group (53 pupils), who carried out physical education classes according to the modified plan and program of sports games (basketball, volleyball and handball) for a semester and a control group (53 pupils) who attended regular classes from physical education according to the current curriculum. The variables applied in this study consisted of 9 variables for assessing situational motor performance in sports games and variables for assessing situational motor performance from basketball (Throwing a hand with a hand on the wall and capturing for 30 seconds - SMKBLRZ; Handling the ball by hand in the slalom - SMKVLS; Throwing the ball into the basket for 30 seconds - SMKBLK), variables for assessing situational motor performance from volleyball (Service bottom chess - SMOSD; Targeting the target through the net from the base bet - SMOGCPM; SMOOLPK), variables for assessing situational motor performance from the handball (Throwing the ball on the wall for 30 seconds - SMRBLZ; Running the slalom ball SMRVLS; Performing the seven-meter - SMRIS). Descriptive statistics, T-test and factor analysis were used to determine qualitative changes in situational motor abilities. The results of the research at the descriptive level showed that there are visible differences in the average values between the same individual groups and between the measurements within the same group in the final versus the initial measurements. The results of the factor analysis show that there were statistically significant qualitative changes, and based on the results of T-tests it can be concluded that they are statistically significant at levels less than $1 \%$ for the SMKVLS variable, and at levels less than $5 \%$ for the variables SMRBLZ and SMRVLS. In the final measurement, there was a change in value and thus a difference in the variables of the SMKBLK after the program of work. In this way it was established that the program led to changes in the value of situational motors, and more so in the experimental group compared to the control. It is reasonable to conclude that such and similar programs in the school of additional classes have great effects on the transformation of the students' desired abilities, if the individual possibilities of students with whom the intended contents are realized are respected.

\section{Acknowledgment}

The authors would like to thank every participant for his effort and time.

\section{Funding}

No external funding was received for this study.

\section{Declaration of Interest}

The authors report no conflict of interest.

\section{References}

Armstrong, N., McManus, A. (1994). Children's fitness and physical activity - a challenge for physical education. British Journal of Physical Education, 2, 2026.

Bajramović, I., Talović, M., Alić, H., Jelesković, E. (2008). Levels of quantitative changes in the specific-motor skills of football players under the influence of situational training. Sport Mont, VI(15, 16, 17), 104109. 
Ćeleš, N. (2009). The influence of programmed exercise on the transformation of morphological characteristics, motor skills and the adoption of elements of volleyball technique. Unpublished Doctoral dissertation, Tuzla: Faculty for Physical Education and Sports.

Džumhur, A. (2009). Effects of the situational method of work on the improvement of basic motor skills and performance in a small football game with children aged 12-14 years. Unpublished Master's thesis, Sarajevo: Faculty of Sports and Physical Education.

Hadžikadunić, A. (2007). Transformation processes of basic motor, situational motor and functional abilities of pupils of the 8th grade under the influence of programmed teaching of physical and health education. Unpublished Master's thesis, Sarajevo: Faculty of Sports and Physical Education.

Lakota, R. (2006). Effects of programmed work on transformation of basic-motor and situational-motor skills of handball players. Unpublished Master's thesis, Sarajevo: Faculty of Sports and Physical Education.

Lakota, R., Talović, M., Jelesković, E., Bonacin, D. (2008). Effects of programmed training on transformation of the qualitative level of situational-motor skills of handball players aged 11-14. Sport Science, 1, 60-64.

Malacko, J., Pejić, A. (2009). Changes in the biomotor dimensions of pupils aged 11 years, the experimental program of sports games in relation to the standard program of physical education. Sport Science, 2(1), 5261.

Mladenović, M. (2008). Structural changes in sports games in the teaching of physical education. Sport Science, 1, 39-43.

Milanović, L. (2007). Methodology of training of speedexplosive properties in children and young people. Fitness preparation of athletes. University of Zagreb: Faculty of Kinesiology, Zagreb.

Prskalo, I., Findak, V. (2003). Methodological organizational forms of work in the function of teaching process optimization. Progress - A Journal for Pedagogical Theory and Practice, 144(1), 53-65.

Skender, N. (2003). Transformation processes of motor skills and anthropological characteristics under the influence of a seven-month treatment in students of the third and fourth grade. Unpublished Doctoral dissertation, Sarajevo: Faculty of Sport and Physical Education.

Stanković, A. (2002). Effects of programmed teaching of physical and health education on some anthropometric characteristics and motor abilities of pupils and students in the fifth class. Unpublished Master thesis, Sarajevo: Faculty of Physical Culture.

Šmoglović, M., Bajrić, O., Lolić, D. (2012). Influence of volleyball program on basic and situational motor skills of students aged 13-14. Sports Sciences and Health, 2(1), 35-40.

Tabaković, M., Skender, N., Turković, S. (2006). Quantitative differences in motor skills of pupils of lower grades of primary school after realization of certain programs, Homosporticus, 9(2), 44-50.

Talović, M., Mahmutović, I., Jelešković, E., Alić, H., Ormanović, Š., Lakota, R., Hadžimehmedović, D., Sedić, D. (2015). Effects of regular and additional teaching of physical and health education on qualitative changes of specific motor skills of pupils. Sports Logos, 24(25), 37-44.

World Medical Association. (2013). World Medical Association Declaration of Helsinki Ethical Principles for Medical Research Involving Human Subjects. JAMA, 310(20). 